\title{
Platelet Function Testing: Auditing Local Practice and Broader Implications
}

\author{
EMMANUEL J FAVALORO, SOMA MOHAMMED
}

\begin{abstract}
BACKGROUND: Platelet function testing is a common test procedure used for assessing patients with mucocutaneous bruising and/or bleeding and for monitoring anti-platelet therapy. However, standardization of practice is poorly applied, and experts differ on several aspects of its application.
\end{abstract}

OBJECTIVE: This study reports on a local audit of current practice in consideration of recent reports, expert opinion and current CLSI guidelines.

METHODS: We undertook an assessment of our laboratory test practice for light transmission aggregometry (LTA) as a diagnostic screening process for platelet function, as well as performance of PFA-100 closure times used for screening primary haemostasis. For LTA testing, we wished to assess the validity or otherwise of platelet count adjustments using autologous platelet poor plasma (PPP), as used by some experts and as also recommended by the current CLSI guidelines for performance of platelet aggregation. For PFA-100 testing, we assessed the effect of different blood collection tubes.

RESULTS: For most test cases undergoing LTA, platelet count adjustment using autologous PPP resulted in considerable diminution of detectable

The peer-reviewed Research and Reports Section seeks to publish reports of original research related to the clinical laboratory or one or more subspecialties, as well as information on important clinical laboratory-related topics such as technological, clinical, and experimental advances and innovations. Literature reviews are also included. Direct all inquiries to David L McGlasson MS, MLS, 59th Clinical Research Division/SGRL, 2200Berquist Dr., Bldg. 4430, Lackland AFB TX 78236-9908, david. mcglasson@lackland.af.mil platelet function using several agonists, and in particular collagen, ADP and epinephrine. These effects could result in differing conclusions regarding the likelihood or severity of a platelet function disorder. For the PFA100 , different blood collection tubes resulted in slightly different closure times that could also potentially influence the conclusion of 'normality' or otherwise for investigated patients.

CONCLUSIONS: This audit of local practice indicates that the process of platelet count adjustment using autologous PPP provides adverse outcomes related to identification of platelet dysfunction. Accordingly, we recommend that all laboratories validate this practice if used at their facility. For PFA-100 testing, local validation of the normal reference range is required according to local conditions and collection practice. Otherwise, laboratories may inappropriately identify platelet function disorders when these may not exist.

ABBREVIATIONS USED: ADP - adenosine diphosphate; CLSI - Clinical and Laboratory Standards Institute; CTs - closure times; C/Epi - collagen/ epinephrine; C/ADP - collagen/adenosine diphosphate; Epi epinephrine; fc -final concentration; LTA - light transmission aggregometry; PPP - platelet poor plasma; PRP - platelet rich plasma; VWD - von Willebrand disease; WBA - whole blood aggregometry.

INDEX TERMS: platelet function tests, PFA-100, light transmission aggregometry.

Clin Lab Sci 2010;23(1):21

Emmanuel J Favaloro BSc (Hon) PhD MAIMS, Department of Haematology, Institute of Clinical Pathology and Medical Research (ICPMR), Westmead Hospital, NSW, Australia. 
Soma Mohammed BSc (BioMed)., Department of Haematology, Institute of Clinical Pathology and Medical Research (ICPMR), Westmead Hospital, NSW, Australia.

Address for Correspondence: Dr. E.J. Favaloro, Department of Haematology, Institute of Clinical Pathology and Medical Research (ICPMR), Westmead Hospital, WSAHS, Westmead, NSW, 2145, Australia, emmanuel .favaloro@swahs.health.nsw.gov.au

\section{INTRODUCTION}

Platelet function testing is a common test procedure used for assessing patients with mucocutaneous bleeding and/or bruising and in some laboratories for monitoring anti-platelet therapy. ${ }^{1,2}$ However, standardization of practice is poorly applied, and experts differ on several aspects of its application. ${ }^{1-6}$ The most common test methods applied for diagnostic screening of platelet function are light transmission aggregometry (LTA) ${ }^{1}$ and whole blood aggregometry (WBA). ${ }^{2}$ In addition, several primary haemostasis or platelet function screening procedures are available, of which the PFA100 is probably the most popular. ${ }^{7,8}$ WBA has several advantages over LTA, including test performance under 'more physiological' conditions (i.e. using whole blood, albeit typically diluted 1:1 with buffer) and reduced processing of blood and platelets prior to testing. ${ }^{2}$ This reduces test time, and also the likelihood of test artefacts (i.e. of identifying false reductions in platelet activity due to over-handling of platelets, which are highly sensitive to adverse processing effects). ${ }^{2}$ Nevertheless, LTA remains the gold standard because it represents the original test methodology and thus has a longer history than WBA, inclusive of research and publication data. ${ }^{1}$

Standardization of platelet function is poorly applied, ${ }^{3-5}$ and experts differ on various test practices. In addition, although internal quality control is feasible, ${ }^{9}$ this is difficult for most laboratories to apply in practice, given the time required for testing (up to 2 or more hours for each individual platelet function test) and the need to collect normal individuals (usually laboratory staff) on a regular, sometimes daily, basis. ${ }^{5}$ External quality assurance of platelet function testing is also largely lacking, despite some recent initiatives from external quality assurance providers. ${ }^{5}$
One of the main differences in regards to expert opinion related to platelet function testing using LTA is the need to adjust the platelet count. Some experts undertake such adjustments as a standard practice, ${ }^{10}$ whereas others warn of the dangers related to loss of platelet activity because of over-handling and refractoriness. ${ }^{11,12}$ The latter is potentially related to dense granule release (or other events) following the high speed centrifugation required to obtain the platelet poor plasma (PPP) needed to dilute the platelet rich plasma (PRP) in order to obtain a standardised platelet count. $^{11}$ The current CLSI guideline ${ }^{13}$ on platelet function testing by LTA recommends undertaking a platelet count adjustment in order to standardise the platelet count to between 200 and $250 \times 10^{9} / \mathrm{L}$, while also noting that some experts disagree with this practice.

Our facility ceased performing platelet count adjustments several years ago, when it became apparent that we were observing 'minor' platelet abnormalities in a high proportion of patient samples, as well as in controls, and potentially related to a change in collection practice. We have therefore undertaken an audit of current practice in order to reinvestigate this issue in relation to LTA testing, while reflecting on current CLSI guidelines, and recent published reports and differing expert opinion. We also decided to briefly re-evaluate local performance of the PFA-100 in the context of platelet function testing. Although these audits have particular relevance to our own test practice, and most likely reflect changes to blood collection practice at our institution, we also propose that these local findings hold substantial implications to the globally applied practice of platelet function testing at many facilities.

\section{MATERIALS AND METHODS}

Patients and blood collection: The patients included in this study were those referred to us for investigation of mucocutaneous bleeding or bruising, other adverse bleeding event(s), or other clinically justified reason(s), and for which platelet function testing was performed by both LTA and PFA-100. Our laboratory does not undertake regular monitoring of anti-platelet therapy within the context of treatment, in agreement with the International Society on Thrombosis and Haemostasis 
(ISTH) Scientific Standardisation Committee (SSC), who advise that the clinical utility of such monitoring requires further evaluation. ${ }^{14}$ It is our standard practice for our platelet function investigations to query recent medication history and to generally decline testing if there is evidence of recent medication likely to affect platelet function. If possible, we also undertake a review of personal and familial history related to bleeding and bruising.

For platelet function testing, we now typically collect a number of 'small-draw' blood collection tubes $(2.7 \mathrm{ml}$ 'Vacutainer' tubes containing 3.2\% buffered sodium citrate; reference number 363095; Becton Dickinson, Sydney, Australia) as well as 'large-draw' blood collection tubes $(9 \mathrm{ml}$ 'Vacuette' tubes containing 3.2\% buffered sodium citrate; reference number 455322; Greiner, purchased from Interpath, Sydney, Australia). Blood is collected by venisection by experienced phlebotomists on site at our facility and generally under our guidance. The above reflects a change of collection practice over the years, due to occupational health and safety concerns related to handling of blood, since in the past, blood was collected by needle into syringes and then gently dispensed into anticoagulant containing tubes without vacuum. This earlier practice aimed to minimise adverse effects on platelet function potentially due to vacuum collection and resulting shear effects.

The 'small-draw' collection tubes are those routinely contracted to our organization. These are used for our general haemostasis and PFA-100 testing, and reflect the test system for which we have previously undertaken normal reference range estimations. ${ }^{15}$ The 'large-draw' blood collection tubes represent those tubes specifically purchased to perform platelet function testing by LTA, and for which validation of usage was previously established. The current report relates to the use of this material differentially within LTA studies or in PFA100 testing.

In addition, a small blood sample is always routinely collected ( $3 \mathrm{ml}$ 'Vacutainer' tubes containing $5.4 \mathrm{mg}$ potassium EDTA (K $\left.\mathrm{K}_{2} \mathrm{EDTA}\right)$; reference number 367838; Becton Dickinson, Sydney, Australia) for routine blood parameters as part of a full (or 'complete') blood count workup. In particular, the platelet count and morphology, as well as the hematocrit, is particularly relevant for LTA and PFA-100 testing.

Platelet function testing by light transmission aggregometry: This was performed similarly to that previously reported, ${ }^{16}$ using a Chronolog platelet aggregometer (Model 560-VS, Chronolog Corpora-tion, Havertown, PA, USA), with the stirrer speed set to $1000 \mathrm{rpm}$. In brief, citrate anticoagulated whole blood $(4 \times 9 \mathrm{ml}$ Greiner Vacuette tubes) was allowed to rest for 15 minutes post-collection and then centrifuged at low speed (120g, 15 minutes, without brake) to isolate PRP. Care was taken not to disturb the plasma cell interface and the top two mls of PRP from each tube was gently transferred (pooled) to a fresh plastic tube, which was then capped to prevent changes in $\mathrm{pH}$. The PRP tube was then gently mixed to homogeneity by inversion and a platelet count performed. The remaining whole blood sample was centrifuged at high speed (1200g, 15 minutes, without brake) to isolate PPP. Care was again taken not to disturb the plasma cell interface and the top two mls of PPP remaining in each tube was gently transferred to a second fresh plastic tube, which was then also capped to prevent changes in $\mathrm{pH}$.

For LTA, 450ul volumes of PRP were transferred to 10 aggregometry tubes containing a siliconised stirrer, and $500 \mathrm{ul}$ of PPP was transferred to a separate aggregometry tube without a stirrer and used as the assay blank tube. All samples were incubated in the resting position of the aggregometer for a minimum of 5 minutes to equilibrate to $37^{\circ} \mathrm{C}$. A test aggregometry tube containing $450 \mathrm{ul}$ of PRP was then transferred to the test position to assess any spontaneous aggregation. Subsequent testing involved adding in sequence a variety of platelet agonists to each separate aggregometry tube, typically at 50ul volumes, to assess specific platelet aggregation responses. Each aggregometry test is monitored for a minimum of 5 minutes, but longer as required to enable the maximum response to be determined. 100\% ('theoretical maximum') aggregation is taken as $100 \%$ light transmittance and is assessed with a PPP blank as the 'test' sample in the test position versus PPP in the blank position. $0 \%$ aggregation is taken as the PRP in the test 
position (without added agonist) versus PPP in the blank position. All tracings are visualised using a chart recorder, and any aggregation above $80 \%$ is considered a maximal response. A minimum response requires at least a $20 \%$ shift in the aggregation response.

The response to the following agonists are now routinely assessed by LTA in our laboratory: (a) ristocetin (Catalogue number 5199; $15 \mathrm{mg} / \mathrm{ml}$; Helena Laboratories, Melbourne Australia), used at two or more concentrations to assess minimum and maximum thresholds (typically over the range $0.2-2.0 \mathrm{mg} / \mathrm{ml}$ final concentration $[\mathrm{fc}]$ ); (b) arachidonic acid (Catalogue number 5364; Helena Laboratories, Melbourne Australia), used at a single concentration (1.6mM final); (c) adenosine diphosphate (ADP; Catalogue number 5366; Helena Laboratories, Melbourne Australia), used at two or more concentrations to assess minimum and maximum thresholds (ie primary and secondary waves of aggregation (typically assessed over the range 0.620.0uM fc)); (d) epinephrine (Catalogue number 5367; Helena Laboratories, Melbourne Australia), used at a single or multiple concentrations to assess primary and secondary waves of aggregation (typical range 10$300 \mathrm{uM} \mathrm{fc}$ ); (e) collagen (HORM Collagen, purchased from Optigen Scientific, Adelaide, Australia), used at two or more concentrations to assess normal thresholds (typically assessed over the range $1.0-10.0 \mathrm{ug} / \mathrm{ml} \mathrm{fc}$ ).

To assess the effect of platelet count adjustments using autologous PPP, a volume of PRP (typically 2-4 ml) was gently mixed with a volume of PPP (typically 2-4 $\mathrm{ml}$ ) to obtain a platelet count of between 200 and $250 \mathrm{x}$ $10^{9} / \mathrm{L}$, as recommended by the current CLSI guidelines. ${ }^{13}$ LTA was performed as per the unadjusted PRP testing described above using the same agonists at either the same and/or alternate (e.g. higher) concentrations, as required to elicit similar or maximal and minimal responses. This audit was performed over a period of around eight months, and assessment of PRP adjustment was only performed on a subset of LTA investigations during this period.

All platelet function testing was performed within 4 hours of collection, as recommended by the CLSI guidelines. ${ }^{13}$
For the purpose of this study, a 'normal' LTA was that which provided test results within our normal limits, ${ }^{16}$ as identified in Table 1 (viz: normal $(>80 \%)$ aggregation to arachidonic acid (@1.6mM fc), normal aggregation with a secondary wave to the 'weak' agonists ADP and epinephrine (respectively $₫ 5 \mathrm{uM}$ and $10 \mathrm{uM} \mathrm{fc}$ ), normal aggregation with the 'strong' agonist collagen (@ minimum of 1ug/ml fc) and normal aggregation to ristocetin (@ between 1.0 and $1.5 \mathrm{mg} / \mathrm{ml}$ fc)).

\begin{tabular}{|c|c|}
\hline \multicolumn{2}{|c|}{ Table 1: Definitions for current LTA study } \\
\hline Normal LTA & $\begin{array}{l}\text { normal }(>80 \%) \text { aggregation to } \\
\text { arachidonic acid (@1.6mM fc), norma } \\
\text { aggregation with a secondary wave to } \\
\text { the 'weak' agonists ADP and } \\
\text { epinephrine (respectively @ } \leq 5 \mathrm{uM} \text { and } \\
10 \mathrm{uM} \mathrm{fc} \text { ), normal aggregation with the } \\
\text { 'strong' agonist collagen (@ minimum } \\
\text { of } 1 \mathrm{ug} / \mathrm{ml} \mathrm{fc} \text { ) and normal aggregation to } \\
\text { ristocetin (@ between } 1.0 \text { and } 1.5 \\
\mathrm{mg} / \mathrm{ml} \mathrm{fc} \text { ). }\end{array}$ \\
\hline
\end{tabular}

possible 'mild' platelet dysfunction

'moderate' platelet dysfunction

significant change in platelet function between unadjusted and adjusted platelet count test results within our normal limits for all the tested agonists excepting for one of the weak agonists and/or collagen

abnormal aggregation results obtained for the weak agonists plus collagen

(i) a change from 'normal' to 'mild' or to 'moderate' platelet dysfunction, or (ii) a change from 'mild' platelet dysfunction to 'moderate' platelet dysfunction
Ristocetin aggregation is used to primarily assess for the possibility of Bernard Soulier Syndrome or variants of von Willebrand disease (VWD). Aggregation using arachidonic acid helps access potential defects in the arachidonic acid pathway or recent aspirin intake.

Aggregation using ADP, epinephrine and collagen is primarily helpful to provisionally identify storage pool deficiency or primary secretion defects for further study if required. For the purpose of this study, a possible 'mild' platelet dysfunction potentially related to these possibilities was defined where test results were within 
our normal limits for all the tested agonists excepting one of the weak agonists and/or collagen, and a 'moderate' platelet dysfunction was defined where abnormal aggregation results were obtained for the weak agonists plus collagen (Table 1). A significant change in platelet function between unadjusted and adjusted platelet count was defined as a change from 'normal' to 'mild' or to 'moderate' platelet dysfunction, or a change from 'mild' platelet dysfunction to 'moderate' platelet dysfunction (Table 1).

PFA-100 testing: This was performed essentially as recommended by the manufacturer except that we routinely use $900 \mathrm{ul}$ whole blood (instead of $800 \mathrm{ul}$ as 'recommended'), since this results in fewer error codes related to 'insufficient sample'. ${ }^{15}$ This is consistent with the maximal tolerance $(1 \mathrm{ml}$ whole blood) of this instrument as advised by the manufacturer, and has been previously validated. ${ }^{15}$ For this study, we employed both test cartridge types, namely collagen/epinephrine (C/Epi) and collagen/adenosine diphosphate (C/ADP), and were interested in any differences in closure times (CTs) obtained with our standard 'small-draw' Vacutainer tubes versus those of our LTA-usage 'largedraw' Vacuette tubes. The data for this part of the report therefore includes all cases investigated by both LTA and PFA-100 over the past 12 months.

Other haemostasis tests: Other associated haemostasis tests, including those for VWD, coagulation factor levels, and routine coagulation tests including the prothrombin time and activated partial thromboplastin time were also performed as required or requested by the clinician referring the patients for investigation, and as per previous reports from our laboratory. ${ }^{17,18}$ As the results of these tests are not specifically reported for the cases under investigation, neither is their test methodology. It is our standard practice to undertake tests related to VWD investigations on all cases referred to us for investigation of mucocutaneous bleeding or bruising, including cases where LTA and/or PFA-100 are performed.

\section{RESULTS}

A total of 11 cases were assessed for LTA over the period of this study with and without adjustment of
PRP platelet count using autologous PPP (Table 2). Although this represents a small sampling, test results post-adjustment were substantially altered in 9/11 (82\%) cases, and so further comparative assessments for this audit were felt to be superfluous. Nine of 11 cases (ie Cases 1-9) represented individuals with personal and/or family history of mucocutaneous bleeding and/or bruising, of varying severity. Using our standard test processes for VWD investigation and LTA without adjustment of PRP platelet count, 2/9 (22\%) of these cases were identified to have possible mild platelet dysfunction, $1 / 9(11 \%)$ possible mild type $1 \mathrm{VWD}$, and $1 / 9$ (11\%) possible mild type 1 VWD plus moderate platelet dysfunction. Only two of these cases (Cases $1 \&$ 2) provided clearly abnormal PFA-100 CTs (with both $\mathrm{C} / \mathrm{ADP}$ and $\mathrm{C} / \mathrm{Epi}$ ), with both cases also yielding test findings suggestive of possible mild type 1 VWD.

One case (Case 10) was a female at 34 weeks gestation with a previous history of Essential Thrombocytosis and thrombosis, referred for investigation because the haematologist had concerns regarding delivery, and this case was found to have normal platelet function plus normal (albeit high levels of) von Willebrand factor. One case (Case 11) had a single event of unexplained but serious bleeding (neural haematoma) plus a previous abnormal platelet function whilst on medication, referred for investigation largely to exclude what may have been a falsely identified (medication related) platelet dysfunction. Interestingly, a possible mild type 1 VWD plus mild platelet dysfunction was identified by testing on this repeat (but medication free) occasion.

Normal aggregation traces from a laboratory control donor using unadjusted PRP is shown in Figure 1. The cases identified in Table 2 as normal for LTA using unadjusted PRP yielded patterns similar to these. Some examples of changes observed in these cases post-platelet count adjustment for arachidonic acid, collagen, ADP and epinephrine, are shown in Figures 2-4. Aggregation in response to ristocetin was normal for all 11 cases, for both unadjusted and platelet adjusted LTA (data not shown). Accordingly, platelet adjustment did not appear to influence aggregation induced by ristocetin. All 11 cases also responded normally to arachidonic acid using both adjusted and unadjusted PRP, confirming 
Table 2: Summary of Case investigations for current LTA study

\begin{tabular}{|c|c|c|c|c|c|c|}
\hline $\begin{array}{l}\text { Case } \\
\text { No. }\end{array}$ & Clinical information & $\begin{array}{l}\text { PFA-100 } \\
\text { Closure } \\
\text { Times }\end{array}$ & $\begin{array}{c}\text { VWD } \\
\text { investigation }\end{array}$ & $\begin{array}{c}\text { LTA } \\
\text { (unadjusted) }\end{array}$ & LTA (adjusted) & $\begin{array}{l}\text { Significant } \\
\text { LTA } \\
\text { difference? }\end{array}$ \\
\hline 1 & $\begin{array}{l}\text { Personal and family history mucocutaneous } \\
\text { bleeding (post surgical, menorrhagia, nose and } \\
\text { gum bleeds); abnormal PFA-100 tests on two } \\
\text { previous occasions }\end{array}$ & abnormal & $\begin{array}{l}\text { possible mild } \\
\text { type } 1 \mathrm{VWD}\end{array}$ & $\begin{array}{l}\text { moderate } \\
\text { platelet } \\
\text { dysfunction }\end{array}$ & $\begin{array}{l}\text { moderate } \\
\text { platelet } \\
\text { dysfunction }\end{array}$ & no \\
\hline 2 & $\begin{array}{l}\text { Personal and family history mucocutaneous } \\
\text { bleeding (post surgical, menorrhagia, bruising); } \\
\text { previous abnormal PFA-100 tests and VWD } \\
\text { investigation suggesting mild Type 1 VWD }\end{array}$ & abnormal & $\begin{array}{l}\text { possible mild } \\
\text { type } 1 \mathrm{VWD}\end{array}$ & normal & $\begin{array}{l}\text { moderate } \\
\text { platelet } \\
\text { dysfunction }\end{array}$ & yes \\
\hline 3 & $\begin{array}{l}\text { Personal history mucocutaneous bleeding } \\
\text { (menorrhagia, bowel and recent spontaneous } \\
\text { bruising); previous VWD studies equivocal; } \\
\text { negative family history }\end{array}$ & normal & normal & normal & $\begin{array}{l}\text { moderate } \\
\text { platelet } \\
\text { dysfunction }\end{array}$ & yes \\
\hline 4 & $\begin{array}{l}\text { Personal and family history mucocutaneous } \\
\text { bleeding (post surgical, menorrhagia, nose, gum) } \\
\text { and spontaneous bruising }\end{array}$ & normal & normal & normal & $\begin{array}{l}\text { mild platelet } \\
\text { dysfunction }\end{array}$ & yes \\
\hline 5 & $\begin{array}{l}\text { Personal and family history mucocutaneous } \\
\text { bleeding (post three pregnancies) and bruising; } \\
\text { probable type } 1 \text { VWD }\end{array}$ & normal & normal & $\begin{array}{l}\text { mild platelet } \\
\text { dysfunction }\end{array}$ & $\begin{array}{c}\text { moderate } \\
\text { platelet } \\
\text { dysfunction }\end{array}$ & yes \\
\hline 6 & $\begin{array}{l}\text { Personal mild history mucocutaneous bleeding } \\
\text { (nose bleeds in youth); previous equivocal VWD } \\
\text { test results }\end{array}$ & normal & normal & normal & $\begin{array}{l}\text { moderate } \\
\text { platelet } \\
\text { dysfunction }\end{array}$ & yes \\
\hline 7 & $\begin{array}{l}\text { Personal history mucocutaneous bleeding (post } \\
\text { cuts, post delivery, menorrhagia, nose) and } \\
\text { bruising; previous abnormal PFA-100 tests }\end{array}$ & normal & normal & normal & $\begin{array}{l}\text { moderate } \\
\text { platelet } \\
\text { dysfunction }\end{array}$ & yes \\
\hline 8 & $\begin{array}{l}\text { Recent personal history bruising; possible mild } \\
\text { menorrhagia; possible family history (bruising); } \\
\text { ?VWD }\end{array}$ & normal & normal & normal & $\begin{array}{l}\text { moderate } \\
\text { platelet } \\
\text { dysfunction }\end{array}$ & yes \\
\hline 9 & $\begin{array}{l}\text { Personal and family history mucocutaneous } \\
\text { bleeding (menorrhagia) and bruising; ?VWD }\end{array}$ & normal & normal & $\begin{array}{l}\text { mild platelet } \\
\text { dysfunction }\end{array}$ & $\begin{array}{l}\text { moderate } \\
\text { platelet } \\
\text { dysfunction }\end{array}$ & yes \\
\hline 10 & $\begin{array}{l}\text { Previous Essential Thrombocytosis and previous } \\
\text { portal vein thrombosis post splenectomy; now } 34 \\
\text { wks gestation; current normal platelet count }\end{array}$ & normal & $\begin{array}{c}\text { normal } \\
\text { (high) }\end{array}$ & normal & normal & no \\
\hline 11 & $\begin{array}{l}\text { Unexplained serious bleeding (neural } \\
\text { haematoma); previous abnormal platelet function } \\
\text { while on medication }\end{array}$ & equivocal & $\begin{array}{l}\text { possible mild } \\
\text { type } 1 \mathrm{VWD}\end{array}$ & $\begin{array}{l}\text { mild platelet } \\
\text { dysfunction }\end{array}$ & $\begin{array}{l}\text { moderate } \\
\text { platelet } \\
\text { dysfunction }\end{array}$ & yes \\
\hline
\end{tabular}




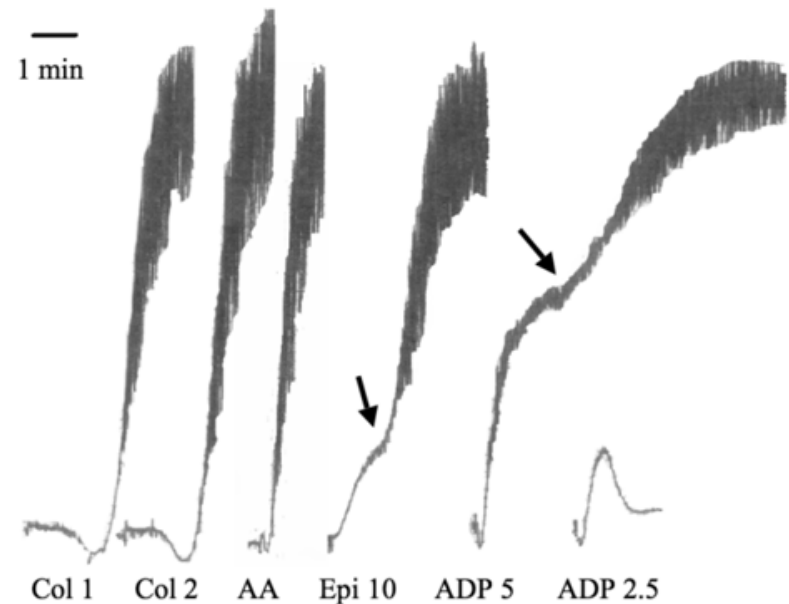

Figure 1. Normal aggregation traces from a laboratory control donor. Shown are results for collagen at $1 \mathrm{ug} / \mathrm{ml}$ and $2 \mathrm{ug} / \mathrm{ml} \mathrm{fc}$ (respectively, labelled as 'Col 1' and 'Col 2' in figure), arachidonic acid (at 1.6mM fc; 'AA'), epinephrine (at 10uM fc; 'Epi 10'), and $\mathrm{ADP}$ (at 5uM and 2.5uM fc; 'ADP 5' and 'ADP 2.5' respectively). Horizontal marker line shows one minute. Arrows in traces for 'Epi 10 ' and 'ADP 5' show the start of the secondary wave of aggregation.

that the cases were aspirin-free and also excluding an arachidonic acid pathway abnormality in these cases. However, we did observe a change in the aggregation tracings for arachidonic acid between unadjusted and platelet adjusted LTA for some cases, with a longer lag phase sometimes present in the latter (two examples are shown in Figure 2).

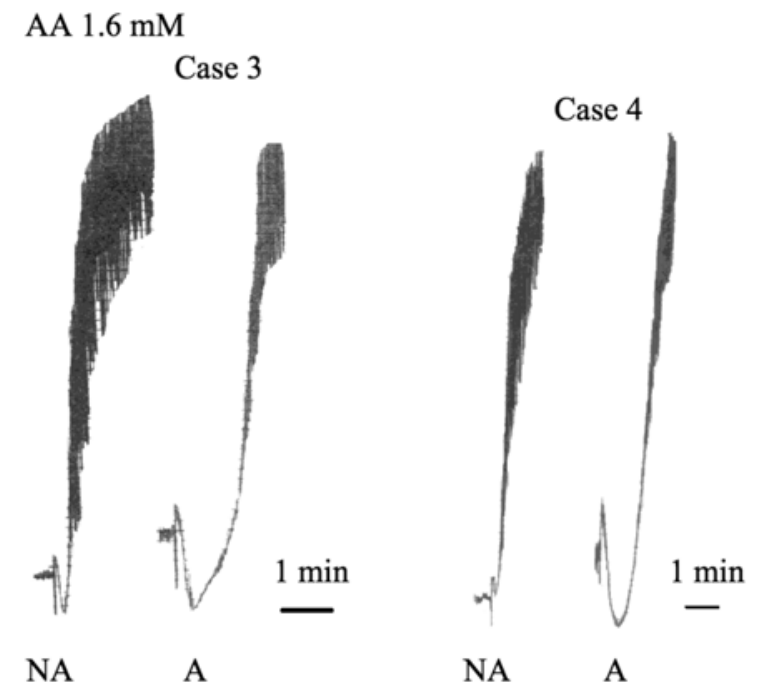

Figure 2. Aggregation tracings for arachidonic acid (using $1.6 \mathrm{mM}$ fc) comparing unadjusted ('NA') and platelet adjusted ('A') LTA for Cases 3 and 4 as examples, showing a longer lag phase in the latter. Horizontal marker line for each case shows one minute.
All cases except Case 1 responded normally to collagen (ie maximal response observed @1 $1 \mathrm{mg} / \mathrm{ml}$ ) when using platelet unadjusted LTA. Interestingly, Case 1 responded normally to a higher concentration of collagen (@2mg/ml) both when using PRP unadjusted and adjusted LTA. Of the remaining 10 cases who had responded to collagen @ $1 \mathrm{mg} / \mathrm{ml}$ using unadjusted LTA, eight failed to aggregate to collagen at the same concentration using platelet adjusted LTA (two examples are shown in Figure 3), with three of these achieving maximal aggregation only above $2 \mathrm{mg} / \mathrm{ml}$.

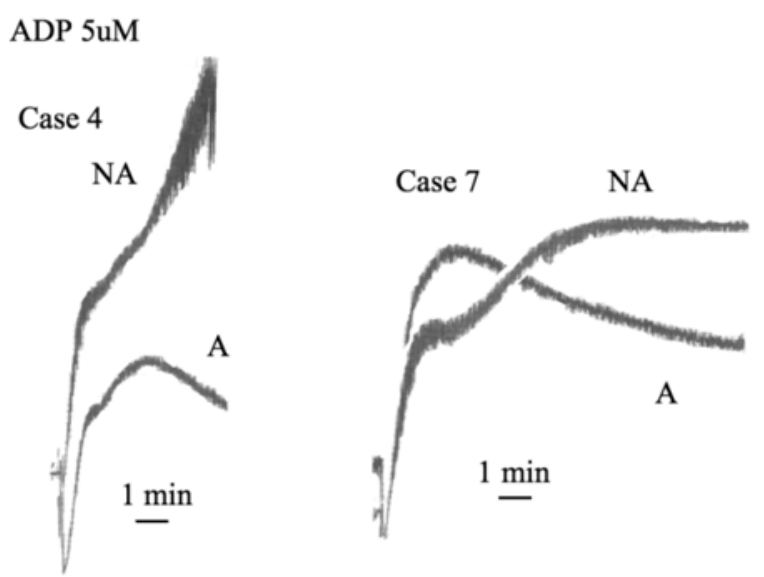

Figure 3. Overlapping aggregation tracings for collagen (using $1 \mathrm{ug} / \mathrm{ml} \mathrm{fc}$ ) comparing unadjusted ('NA') and platelet adjusted ('A') LTA for Cases 3 and 4 as examples, showing normal aggregation in the former, but shape change only, in the latter. Horizontal marker line for each case shows one minute.

Finally, of those cases $(n=7)$ yielding a normal secondary wave of aggregation to ADP and/or epinephrine using unadjusted LTA, all either responded with a secondary wave only at a higher concentration of agonist or else failed to generate a secondary wave in response to the agonist even when used at a higher agonist concentration (two examples for each agonist are shown in Figure 4).

Data related to the PFA-100 audit is shown in Figure 5. Test results using the 'large' draw blood collection tubes gave generally higher closure times compared to our standard 'small' draw collection tubes, although in most test cases there was no change in interpretation of test findings (eg originally normal PFA-100 closure times using small draw tubes were also generally normal with the large draw tubes). 


\section{RESEARCH AND REPORTS}

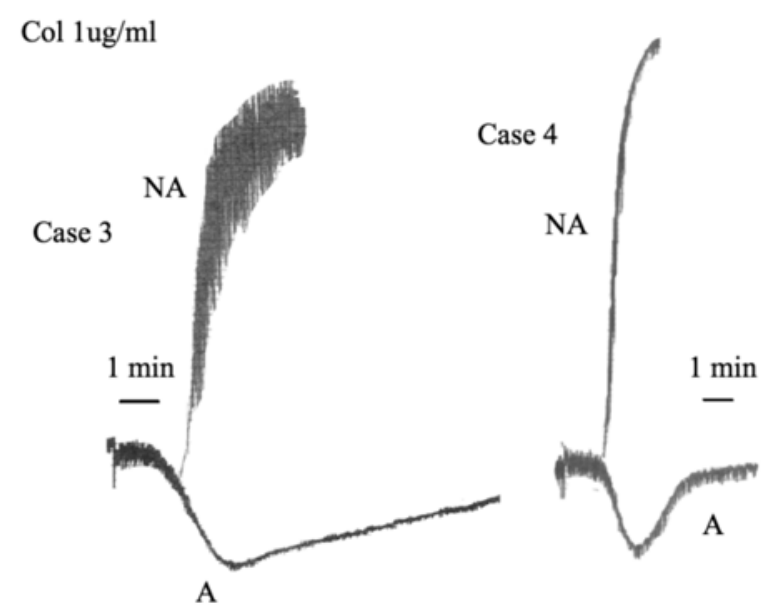

Figure 4a. Overlapping aggregation tracings for ADP (using 5uM fc) comparing unadjusted ('NA') and platelet adjusted ('A') LTA for Cases 4 and 7 as examples, showing normal aggregation with a secondary wave in the former, but disaggregation in the latter.

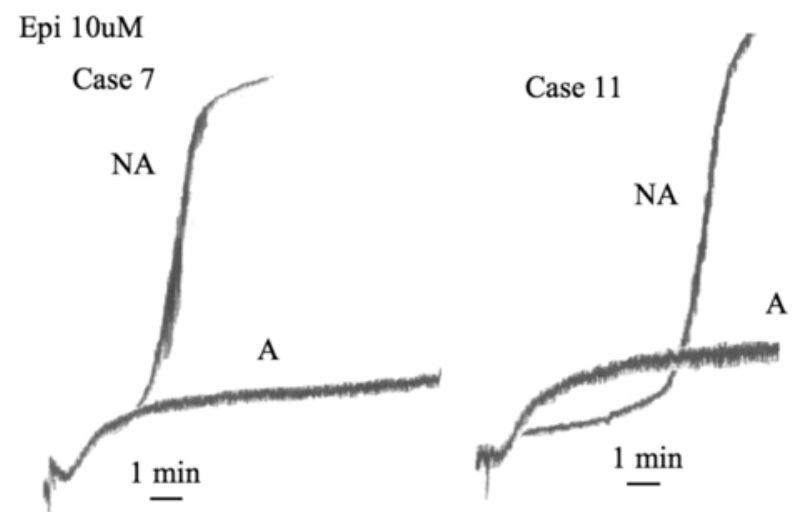

Figure 4b. Overlapping aggregation tracings for epinephrine (using $10 \mathrm{uM} \mathrm{fc}$ ) comparing unadjusted ('NA') and platelet adjusted ('A') LTA for Cases 7 and 11 as examples, showing normal aggregation with a secondary wave in the former, but primary wave only in the latter. Horizontal marker line for each case shows one minute.

\section{DISCUSSION}

LTA is utilized as a diagnostic or diagnostic-screening process for a wide variety of platelet disorders as well as for some cases of VWD. Nevertheless, standardization of platelet function is poorly applied, ${ }^{3-5}$ internal quality control is feasible 9 but difficult to apply, ${ }^{5}$ external quality assurance is largely lacking, ${ }^{5}$ and experts differ on various test practices including the issue of platelet count adjustment. ${ }^{10-13}$ In this respect, the current audit has clearly shown that the practice of platelet count adjustment using autologous PPP for our local practice results in adverse outcomes for the vast majority of cases under investigation. Thus, using platelet adjusted LTA would have resulted in a conclusion of possible 'mild' or 'moderate' platelet dysfunction in 10/11 cases evaluated in this audit, whereas use of non-adjusted LTA would have identified only $4 / 11$ of these cases as possible 'mild' or 'moderate' platelet dysfunction. Most detected abnormalities when using non-adjusted LTA related to lack of a secondary aggregation wave to weak agonists, which is otherwise evident in some $10-20 \%$ of normal individuals, but which is more common in individuals with mucocutaneous bleeding. ${ }^{6,10,19}$ There is no doubt in our mind that the non-adjusted LTA findings represent the more diagnostically correct findings, and that the post-adjusted LTA findings represent several false positive events related to handling issues.

Although the CLSI guidelines ${ }^{13}$ recommend adjusting platelet count to help standardize the assay, several workers in the field advise against doing so because this may lead to diminution of platelet responsiveness, potentially due to dense granule release. ${ }^{11,12,20}$ The likelihood of such events would depend on the blood collection process and the extent of platelet manipulation. In the past, our practice was to collect blood for LTA by a large bore (e.g. 19 gauge) needle directly into syringes and then to gently dispense this blood into tubes containing anticoagulant. Due to occupational health and safety concerns related to handling of blood in this manner, our facility was required to change practice and to utilise commercial blood collection tubes with blood collected under vacuum with guards. Prior to undertaking this change, we validated the use of such collections, but noted ongoing high rates of 'mild' defects, namely lack of secondary aggregation waves to ADP and/or epinephrine, when samples were platelet count adjusted. Accordingly, since platelet unadjusted LTA using the new collection process better correlated to our previous experience we made a conscious decision to stop undertaking such adjustments.

Therefore, it is very likely that the high rate of detection of these 'false' mild platelet function defects using platelet adjusted LTA within our study reflects local 
A.

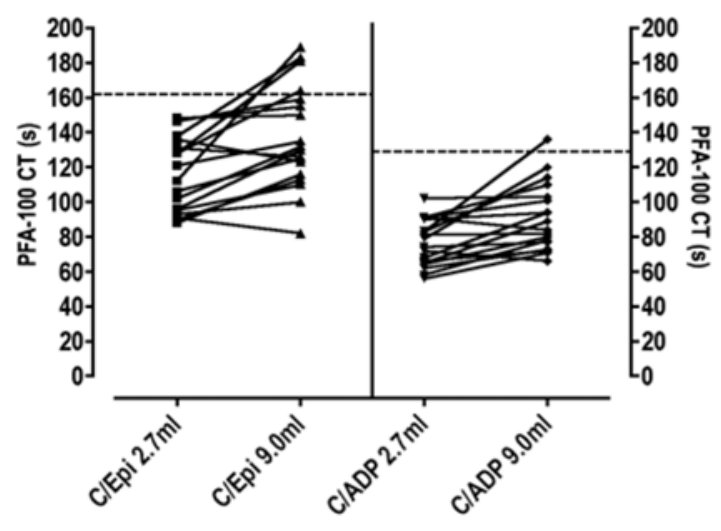

Test and blood collection tube

C.

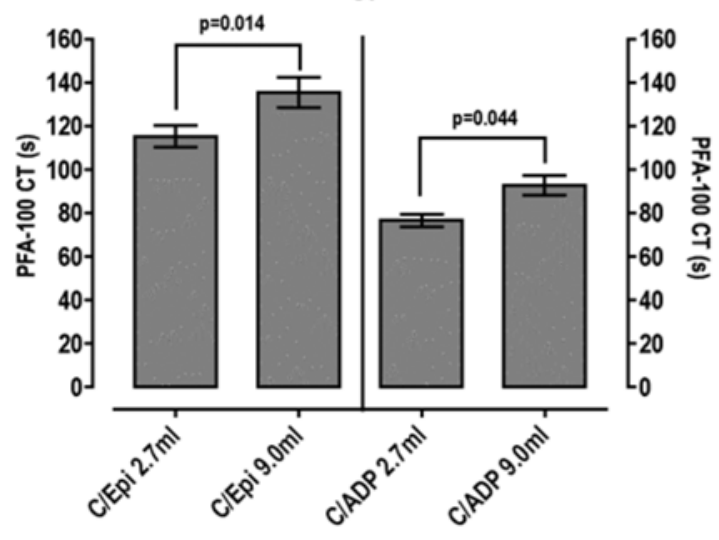

Test and blood collection tube
B.

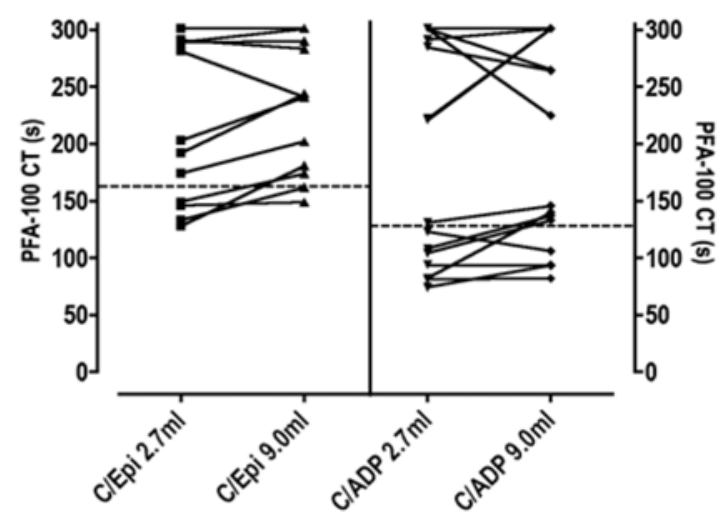

Test and blood collection tube

D.

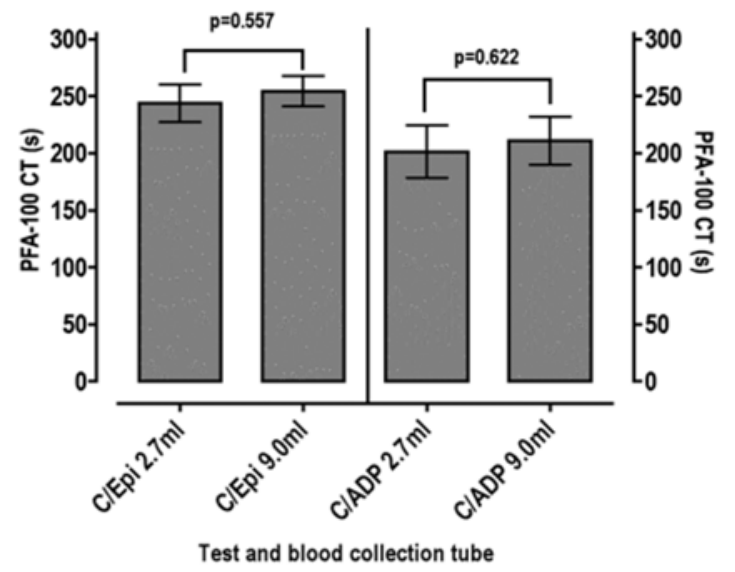

Figure 5: PFA-100 closure times (CTs; $y$-axis in seconds) using collagen/epinephrine (C/Epi) and collagen/adenosine diphosphate (C/ADP) test cartridges and comparing 'small' draw $(2.7 \mathrm{ml})$ blood collection tubes versus 'large' draw $(9.0 \mathrm{ml})$ blood collection tubes. Figures A and B show data as a paired dot plot and separating data according to test samples providing originally normal CTs using small draw tubes (Figure A) versus those providing originally abnormal CTs using small draw tubes (Figure B). There was a modest rise in CTs for most test cases using the large-draw tubes, which was especially evident for normal CTs (Figure A). Figures C and D respectively show the same data as A and B, but graphed as bars showing mean and SEM of data set. There was a significant change between the means for normal CTs (Figure C).

issues related to use of blood collected into large collection tubes under vacuum. It is therefore possible that platelet count adjustment will not universally result in such high rates of false positive defects when collected at other facilities using different collection processes. Nevertheless, our findings do have potential implications for at least a proportion of facilities undertaking LTA, and also highlight the danger in undertaking such adjustments without confirming that this is without adverse consequence. Thus, despite the current CLSI guidelines recommending platelet count adjustments, we recommend that laboratories undertaking platelet adjusted LTA audit this practice at their institution to validate this process is without adverse consequence. If platelet count adjustment is considered to still be required, a potential proposed alternative to the use of autologous PPP is a suitable isotonic buffer. ${ }^{13}$

In a previous audit of our geographic locality, 30/36 $(83 \%)$ laboratories undertaking LTA perform platelet count adjustments. ${ }^{21}$ However, for our own facility, we 
find platelet count unadjusted LTA to provide the more acceptable diagnostic screening procedure, providing that the platelet count is within the range 150-600 $\mathrm{x} 10^{9} / \mathrm{L}$. This is also the experience of others. ${ }^{11}$ Platelet counts above this for PRP for unadjusted LTA are rarely encountered for investigation of mucocutaneous bleeding, but may still provide valid results, although a parallel assessment using a platelet count adjusted LTA would be considered on a case by case basis.

For the PFA-100 audit, we observed a slight prolongation of CTs using the 'large-draw' tubes compared to the 'small-draw' tubes, particularly for normal CTs (Figure 5). The reason for this is unknown, given these tubes reflect identical citrate concentrations. However, PFA-100 CTs are recognised to be influenced by a variety of analytical variables, including platelet count, hematocrit, platelet activity and von Willebrand factor level and activity. ${ }^{8}$ Accordingly, subtle changes to any of these parameters between the collection tubes could feasibly affect CTs (e.g. tube fill characteristics could feasible result in slight differences in relative citrate:blood volume fill; alternatively, large fill vacuum effects may cause a slight diminution of platelet activity). In any case, laboratories are advised to validate normal reference ranges whenever a change in collection tube is undertaken, even if the collection tubes contain the same additive, and especially if there is a change in the size of the blood draw per tube.

\section{CONCLUSION AND RECOMMENDATIONS}

In conclusion, platelet count adjustment using autologous PPP can lead to a high rate of false identification of platelet abnormalities. Although our findings may largely reflect local issues, and not be representative of LTA testing using platelet count adjustment at all facilities, we recommend that laboratories undertaking platelet adjusted LTA, audit this practice at their institution to validate that this process is without adverse consequence. We also believe that the CLSI guidelines on platelet function testing should be reviewed in light of such findings, particularly if further validation of these findings comes to light.

Finally, it is important to recognize that, despite an extensive laboratory investigation of individuals suffering from mucocutaneous bleeding/bruising, laboratories will fail to identify a laboratory defect in upwards of $50 \%$ of these individuals. ${ }^{622-24}$ Accordingly, the failure of a laboratory to define a defect in any given individual does not necessarily reflect a failing of that particular laboratory's practice, but rather the limitation of currently available laboratory testing.

Clin Lab Sci encourages readers to respond with thoughts, questions, or comments regarding this article. Email responses to westminsterpublishers@comcast.net. In the subject line, please type "CLIN LAB SCI 23(1) RE FAVALORO”. Selected responses will appear in the Dialogue and Discussion section in a future issue. Responses may be edited for length and clarity. We look forward to hearing from you.

\section{REFERENCES}

1. Cattaneo M. Light transmission aggregometry and ATP release for the diagnostic assessment of platelet function. Semin Thromb Hemost 2009;35:158-67.

2. McGlasson DL, Fritsma GA. Whole blood platelet aggregometry and platelet function testing. Semin Thromb Hemost 2009;35:168-80.

3. Hayward CP, Eikelboom J. Platelet function testing: quality assurance. Semin Thromb Hemost 2007;33:273-82.

4. Pai M, Hayward CP. Diagnostic assessment of platelet disorders: what are the challenges to standardization? Semin Thromb Hemost 2009;35:131-8.

5. Favaloro EJ. Internal Quality Control and External Quality Assurance of Platelet Function Tests. Semin Thromb Hemost 2009, 35:139-49.

6. Mezzano D, Quiroga T, Pereira J. The level of laboratory testing required for diagnosis or exclusion of a platelet function disorder using platelet aggregation and secretion assays. Semin Thromb Hemost 2009;35:242-54.

7. Harrison P, Mumford A. Screening tests of platelet function: update on their appropriate uses for diagnostic testing. Semin Thromb Hemost 2009;35:150-7.

8. Favaloro EJ. Clinical Utility of the PFA-100. Semin Thromb Hemost 2008; 34:709-33.

9. Hayward CP, Moffat KA, Pai M, Liu Y, Seecharan J, and others. An evaluation of methods for determining reference intervals for light transmission platelet aggregation tests on samples with normal or reduced platelet counts. Thromb Haemost 2008;100:134-45.

10. Hayward CP, Pai M, Liu Y, Moffat KA, Seecharan J, Webert $\mathrm{KE}$, and others. Diagnostic utility of light transmission platelet aggregometry: results from a prospective study of individuals referred for bleeding disorder assessments. J Thromb Haemost 2009;7:676-84.

11. Cattaneo M, Lecchi A, Zighetti ML, Lussana F. Platelet 
aggregation studies: autologous platelet-poor plasma inhibits platelet aggregation when added to platelet-rich plasma to normalize platelet count. Haematologica 2007;92:694-7.

12. Mani H, Luxembourg B, Kläffling C, Erbe M, Lindhoff-Last E. Use of native or platelet count adjusted platelet rich plasma for platelet aggregation measurements. J Clin Pathol 2005;58:747-50.

13. CLSI. Platelet Function Testing by Agggregometry; Approved Guideline. CLSI document H58-A. Wayne, PA: Clinical and Laboratory Standards Institute; 2008.

14. Michelson AD, Cattaneo M, Eikelboom JW, Gurbel P, Kottke-Marchant K, and others. Platelet Physiology Subcommittee of the Scientific and Standardization Committee of the International Society on Thrombosis and Haemostasis; Working Group on Aspirin Resistance. Aspirin resistance: position paper of the Working Group on Aspirin Resistance. J Thromb Haemost 2005;3:1309-11.

15. Favaloro EJ, Kershaw G, Bukuya M, Hertzberg M, Koutts J. Laboratory diagnosis of von Willebrand Disorder (VWD) and monitoring of DDAVP therapy: Efficacy of the PFA- $100^{\circledast}$ and VWF:CBA as combined diagnostic strategies. Haemophilia 2001; 7:180-9.

16. Rasko JEJ, North K, Favaloro EJ, Grispo L, and Berndt MC. Attenuated platelet sensitivity to collagen in patients with Neurofibromatosis Type 1. Br J Haematol 1995; 89: 582-8.

17. Favaloro EJ, Soltani S, McDonald J, Grezchnik E, Easton L, Favaloro JWC. Reassessment of ABO-blood group, gender and age on laboratory parameters used to diagnose von Willebrand Disorder (VWD): Potential influence on the diagnosis versus the potential association with risk of thrombosis. Am J Clin Pathol 2005; 124: 910-17.

18. Favaloro EJ, Soltani S, McDonald J, Grezchnik E, Easton L.
Cross-laboratory audit of normal reference ranges and assessment of ABO-blood group, gender and age on detected levels of plasma coagulation factors. Blood Coag Fibrinolysis 2005; 16:597-605.

19. Quiroga T, Goycoolea M, Panes O, Aranda E, Martínez C, and others. High prevalence of bleeders of unknown cause among patients with inherited mucocutaneous bleeding. A prospective study of 280 patients and 299 controls. Haematologica 2007;92:357-65.

20. Linnemann B, Schwonberg J, Mani H, Prochnow S, LindhoffLast E. Standardization of light transmittance aggregometry for monitoring antiplatelet therapy: an adjustment for platelet count is not necessary. J Thromb Haemost 2008;6:677-83.

21. Duncan EM, Bonar R, Rodgers SE, Favaloro EJ, Marsden K. Methodology and Outcomes of Platelet Aggregation Testing in Australia, New Zealand and the Asia-Pacific Region: Results of a Survey from the Royal College of Pathologists of Australasia Haematology Quality Assurance Program. International J Lab Hematol, 2009; 31:398-406.

22. Pereira J, Quiroga T, Mezzano D. Laboratory assessment of familial, nonthrombocytopenic mucocutaneous bleeding: a definitive diagnosis is often not possible. Semin Thromb Hemost 2008;34:654-62.

23. Quiroga T, Goycoolea M, Panes O, Aranda E, Martínez C, and others. High prevalence of bleeders of unknown cause among patients with inherited mucocutaneous bleeding. A prospective study of 280 patients and 299 controls. Haematologica 2007;92:357-65.

24. Favaloro EJ. Investigating people with mucocutaneous bleeding suggestive of primary haemostatic defects: Low likelihood of definitive diagnosis? Haematologica, 2007; 92: 292-6.

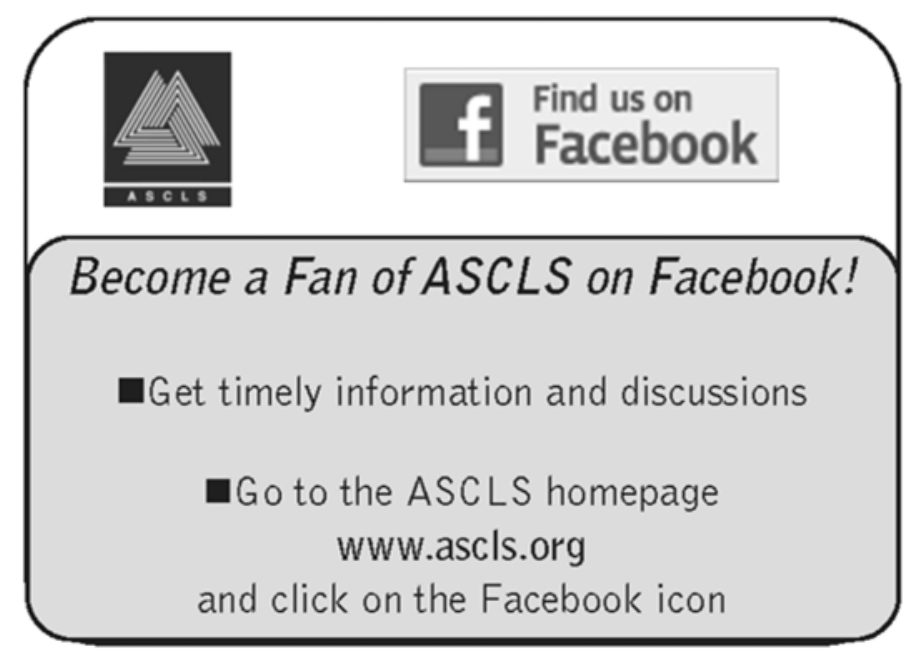

